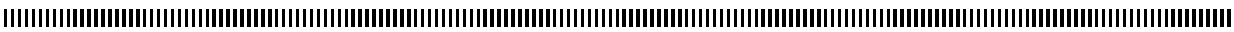

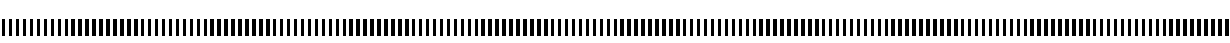

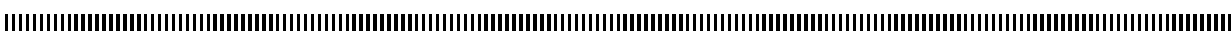

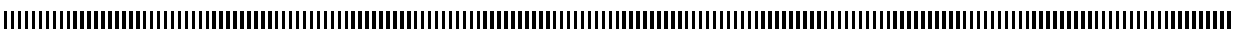

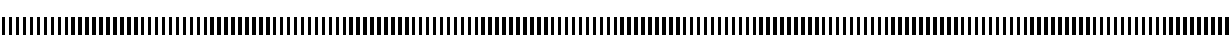

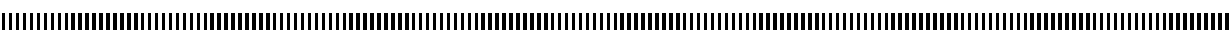

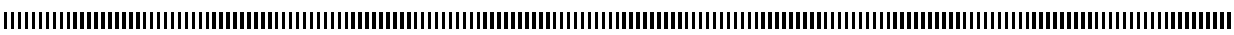

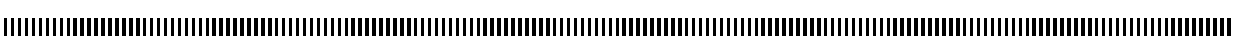

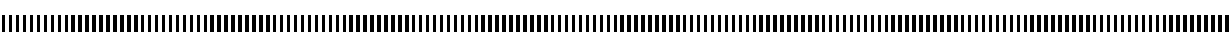

\title{
Efficient controller synthesis of multi-energy systems for autonomous domestic water supply
}

\author{
G. NZEBOP NDENOKA ${ }^{a, c}-$ E. SIMEU ${ }^{b}-$ R. ALHAKIM ${ }^{b}$ \\ a UMI 209 UMMISCO, University of Yaoundé I, P.O. Box 337 Yaoundé, Cameroon. \\ ndenokag@yahoo.fr \\ b University of Grenoble Alpes, TIMA Laboratory, 46 Avenue Félix Viallet, 38031 Grenoble Cedex \\ France. \{Rshdee.Alhakim, Emmanuel.Simeu\} @imag.fr
}

c LIRIMA, IDASCO Team, Department of Computer Science, Faculty of Sciences, University of Yaoundé I , P.O. Box 812 Yaoundé Cameroon.

|

ABSTRACT. The continuous development of ICT facilitates the emergence and rapid proliferation of a wide variety of low-cost processors for the execution of programs in complex embedded applications. In this paper, the study explores the possibility to benefit from this wealth of computing capacity at a reasonable cost to solve concrete problems encountered in implementation of sustainable development processes, particularly in water and energy supply ... We are focusing autonomous water supply in buildings of several floors using several tanks supplied by several sources of water and pumping energy, based on a multilevel hierarchical priority access to water. The first problem is to propose pumping devices and a switching process between power sources, associated to an architectural structure guaranteeing significant reduction of pumping energy. The second problem is the system controller realization. For this, we have proposed a generic architecture justified by gains in potential energy. We also propose an automatic generation tool of control programs for different microprocessor targets taken from the functional design specification of the system given in a Grafcet form. To put them in evidence, we describe at the end a case study.

RÉSUMÉ. Le développement vertigineux des TIC favorise l'émergence et la prolifération rapide d'une grande variété de processeurs à bas coût destinés à l'exécution de programmes embarqués dans des applications complexes. Dans ce papier, l'étude explore la possibilité de tirer profit de cette profusion de capacité de calcul à coût raisonnable pour résoudre des problèmes concrets que l'on rencontre dans la mise en place de processus de développement durable, notamment ceux liés à l'approvisionnement en eau et en énergie ... Nous visons l'étude d'approvisionnement en eau autonome des bâtiments à plusieurs étages, en utilisant plusieurs citernes de stockage approvisionnées par plusieurs sources d'eau et d'énergie de pompage, basée sur plusieurs niveaux hiérarchisés de priorité d'accès à l'eau. Le premier problème est de proposer des dispositifs de pompage et un processus de commutation entre les sources d'énergie, associé à une structure architecturale garantissant une réduction significative de l'énergie de pompage. Le second problème est la réalisation du contrôleur. Pour cela, nous proposons une architecture générique justifiée par des gains d'énergie potentielle. Nous proposons aussi un outil de génération automatique de programmes de contrôle pour différentes cibles à microprocesseur à partir d'une spécification fonctionnelle sous la forme d'un Grafcet. Pour les mettre en évidence, nous décrivons à la fin un cas d'étude.

KEYWORDS : ICT, sustainable development, water supplying, photovoltaic energy, Grafcet modeling, automatic synthesis, logic controller.

MOTS-CLÉS : TIC, dveloppement durable, approvisionnement en eau, énergie photovoltaque, modélisation Grafcet, synthèse automatique, contrôleur logique. 


\section{Introduction}

Information and Communication Technologies (ICT) have undergone enormous evolution in recent years. These changes have led to significant improvements in many application fields such as health care, education, commerce, ... Automation is considered one of the most important sectors which has remarkably been developed thanks to the ICT revolution. For example, almost all digital devices, used to control automated electromechanical systems are nowadays based on sophisticated small microcontrollers instead of hard wired logic components (such as relays, cam timers, drum sequencers), that contribute explicitly to save time, energy, materials and money. Despite all these available advantages, sustainable development applications are slow to benefit from these to solve some implementation problems, such as energy and water distribution issues. For example, in 2013 Cameroon National Institute of Statistics (INS) declared that "almost $92 \%$ of households in Yaoundé suffer from intermittent water cuts.". Hence, "To reduce the shortages, households depend on the following sources: public water supply (55\%), mineral water (10\%), drilled wells (6\%) and other undrinkable water sources (29\%)." [6].

The use of multiple water supply sources is a feasible solution allowing to face the recurring interruptions of urban water supply services. There are, however, a number of problems: some sources (wells/drillings) require electrical energy to operate. This energy can itself even be available in several possibilities including classical urban energy distribution as well as local sustainable sources. However, whether water or energy sources, their costs differ from one another. A management strategy must therefore be implemented to select available sources that are least costly at each operating time.

The importance to invest on renewable energy sources (such as solar energy, wind energy,... $)$ is highlighted to permanently improve the availability of water $([7,10])$. An optimization method is proposed in [11] to minimize energy consumption and to reduce leakage in a water distribution system (WDS) in a hydraulic context. However, the proposed algorithm cannot be applied in a context of household. A model of multi-criteria optimization for energy efficiency has been presented in [10]. But none of the existing methods presents the operational way of handling the issue of energy and water sources management.

The objective of this paper is to study energy control strategy for water supply problem in buildings having many floors. Precisely, it is to find solution that combines sustainable solutions and the advantages of ICT tools in order to realize a complete and autonomous system for water and power supply, with a particular emphasize on saving energy. This involves the establishment of appropriate pumping mechanisms and an efficient process of switching between energy sources. The smart system should guarantee the continuous providing of water to households, and automatically switch between several water and power resources according to the source availability and the service costs.

For ICT tools applied on the automation applications, International Electrotechnical Commission (IEC) has issued five standard programming languages defined in the IEC 6331-3 standard [9]. Among them, Grafcet (or SFC) is a powerful graphical language useful for both specification and programming of industrial automation systems [5]. It is nowadays considered as one of the most used specification languages of IEC standard. Many research works have been carried out to promote and popularize this language, and many modeling and simulation tools as UniSim $([1,8])$, PLCopen XML [13], Isagraf, 
... are based on Grafcet standard. On the other hand, the Grafcet language has actually been built and developed to be integrated in the design and implementation software for programmable logic controllers (PLC) devices $([1,4,12])$.

PLC are digital devices basically used to control automated electro-mechanical systems. They are specially designed to survive in harsh industrial situations and could not be recommended for other simpler control applications. Hence, they are relatively expensive for developing countries and are not required to be operated in corresponding environments. Our investigations on Grafcet synthesis have permitted to carry out a novel software tool that permits to automatically convert any Grafcet specification code to a control program deployable on very economic microcontrollers. This tool is presented and can be exploited to generate the appropriate solution once the system is well specified in Grafcet language.

The paper is organized as follows: Section 2 presents the problem to be solved with different configurations; the proposed model is explained in Section 3. Section 4 presents the study of the logic controller modelling using Grafcet and a solution synthesis approach to obtain an automatic control system. Section 5 draws a case study with the corresponding Grafcet model and conclusions are drawn in Section 6.

\section{Problem statement}

Consider a water providing system, associated to a building having $m$ floors, $n$ water supply sources, $p$ energy sources used to pump water, and $k$ tanks. Each floor of the building is supplied in water by a specific tank until the tank is empty. When the corresponding tank is empty, the connected floors are stocked by a global supply pipe connected to urban water distribution or to the highest tank of the plant.

\subsection{Water storage of tanks}

As shown in Figure 1, each tank is supplied with water by the descent of rainwater, by pumping water from the lower tank, or by opening water supplied by the urban network water distribution. Each tank supplies $k$ floors of the building (for example $k=3$ ). Each $\operatorname{tank} T_{i}$ is equipped with three water level sensors which indicate the empty tank $\left(b T_{i}\right)$, the full tank $\left(h T_{i}\right)$ and the average water level $\left(m T_{i}\right)$. There are two ways of conveying water from sources to tanks: energy-free filling with rainwater and the pumping based filling. The urban water is also used to supply the floors when the first two sources are not supplied.

\subsection{Energy-free filling}

During the rains, the tanks are filled by rainwater harvested from the roofs.

Filling is done sequentially by going from the top tank to the lowest. In the case of low rainfall, the sequential of the tanks filling makes it possible to stock the water collected in priority in the tanks which have the highest potential energy. Especially, the filling of $T_{i}$ is possible if the upper tank $T_{i+1}$ is already full $\left(h T_{i+1}=1\right)$. 


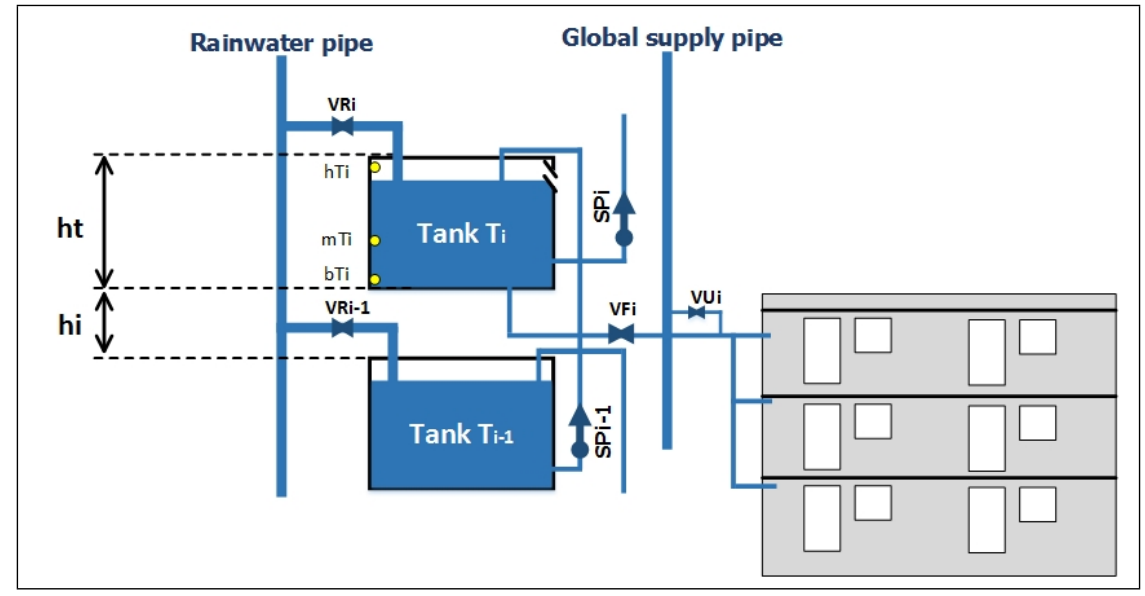

Figure 1. Schematic of an intermediary tank

The filling of the tank $T_{i}$ consists in opening the valve $V R_{i}$ when all the other valves $V R_{j}(j \neq i)$ are closed. The filling ends when the tank $T_{i}$ is filled $\left(h T_{i}=1\right)$, the valve $V R_{i}$ is then closed and the filling of the tank $T_{i-1}$ can begin.

\subsection{Filling by pumping}

In the absence of rain, the pumping allows to supply water to the tank $T_{i}$. It consists in activating the pump $S P_{i-1}$ which transfers water from the tank $T_{i-1}$ to the tank $T_{i}$. Depending on the form of energy used to supply the pump, we can distinguish 3 pumping modes :

\section{- Pumping with the sun}

In this pumping mode, water pumping from the tank $T_{i-1}$ to the tank $T_{i}$ is done without energy costs with solar water pumps that work with an electric motor whose power comes from photovoltaic cells located on solar panels that capture power from the sun's light.

In the presence of sufficient solar brightness $(s r l=1)$, this zero energy cost pumping mode is systematically activated until the tank $T_{j}$ is full $\left(h T_{i}=1\right)$ or the water level in tank $T_{i-1}$ is under average level $\left(m T_{i-1}=0\right)$. This pumping mode is especially suited to rural environments in Africa. This is because sunlight is plentiful (with over six hours per day of maximum sunlight) and sufficient even for large quantity pumping, and the isolation of rural villages often makes it difficult to supply them with conventional energy supplies. Otherwise the need for water in rural village is generally low enough that it can be covered by solar pumping.

\section{- Pumping with battery}

During the night or when the solar radiation is insufficient, the pump $S P_{i-1}$ is activated using batteries power supply when the level of water in the tank $T_{i}$ is below the lower level $\left(b T_{i}=0\right)$. This pumping mode is activated until the tank $T_{i}$ is full $\left(h T_{i}=1\right)$ or the water level in tank $T_{i-1}$ is under average level $\left(m T_{i-1}=0\right)$.

Batteries accumulate excessive energy created by the photovoltaic (PV) panel system and store it to be used at night when there is no more solar energy input. Batteries can discharge rapidly and yield the current charging, ... For PV water pumping application, peep-cycle batteries are suitable to deliver few amperes required for pumping for hundreds of hours between charges. This type of battery is capable of many repeated deep cycles 
and are best suited for PV power systems, compared to shallow-cycle batteries, as those used for starting a car that are designed to deliver several hundred amperes for a few seconds, then the alternator takes over and the battery is quickly recharged. These two types of batteries are designed for different applications and should not be interchanged. Ideally, a battery bank should be sized to be able to store power for 5 days of autonomy during cloudy weather. If the battery bank is smaller than 3 days pumping capacity, it is going to cycle deeply on a regular basis and the battery will have a shorter life. System size, individual needs and expectations will determine the best battery size for your system.

The energy cost of this pumping mode is almost zero because the cost is limited to the maintenance of the battery whose wear is induced by multiplicity of charge/discharge cycles.

\section{- Pumping with urban electricity}

During the nights when the batteries are faulty, power supply pumps is ensured by the urban electricity network. This method of pumping is costly since it is invoiced gradually and paid periodically to the urban electrification agency.

To reduce the energy cost, this mode of operation will be applied only if the corresponding tank is below the low level $\left(b T_{i}=0\right)$ and stops when the middle level is reached $\left(m T_{i}=0\right)$.

\subsection{Purchasing to the urban distribution network}

The urban network water distribution is realized by a public or private company. We assume that this network system guarantees to furnish sufficient pressure to propel water to the upper tank $T_{k}$ without a need of any auxiliary pumping equipment. When a tank $T_{i}$ is empty $\left(b T_{i}=0\right)$ and it is not possible to fill it with rainwater nor the water coming from the tank $T_{i-1}$, the floors of $T_{i}$ are stocked by a global supply pipe connected to the urban water distribution or to the highest tank of the plant (as shown on Figure 3 ).

\subsection{Input/Output configuration of an Intermediary tank}

Considering the previous description, the input/output configuration of the controller of an intermediary tank $T_{i}$ is described by the model presented in Figure 2.

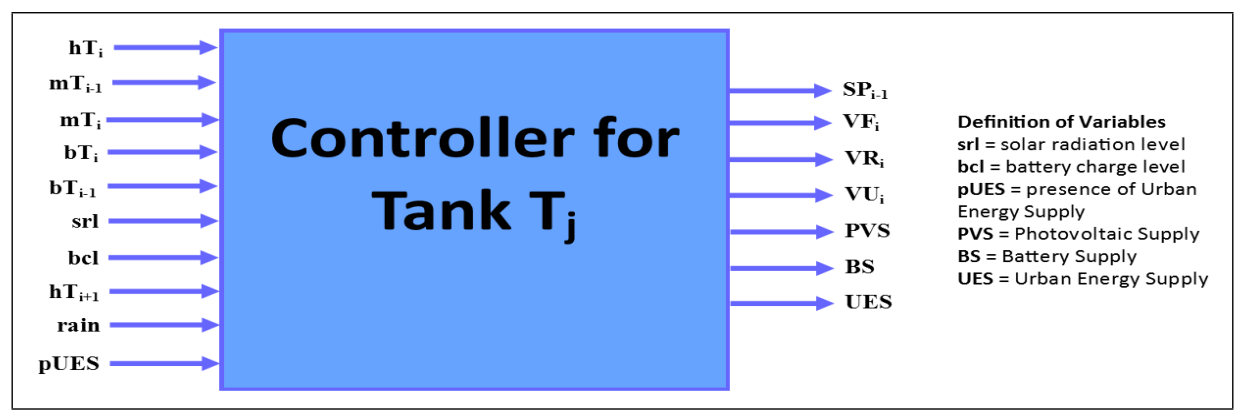

Figure 2. Input/output configuration of the controller of tank $T_{i}$ 


\section{Proposed model}

Once presented the key concepts of the architectural structure with pumping devices and priorities between water sources and power sources, we propose here a switching process that guarantees a significant reduction of pumping energy. In fact, each switching process permits to obtain a particular architectural structure.

There exists many possible switching processes associated to architectural structures and presenting different gain of energy. They depend on many factors: the number of tanks $k$, the position of tanks with respect to floors, the pumping mechanisms, ... Whatever be the case, the final aim is to choose an architectural structure permitting to guarantee the supplying of every floor of the building with significant reduction of pumping energy.

\subsection{Architectural structure}

Generally, we may have any number $k$ of tanks. In the case where there is only one tank $(k=1)$, that tank should supply water in all the floors of the building, which means that it would be situated above all the floors. It is then possible that the rainwater is not collected due to the position of that unique tank, which is relatively above the roof. However, if the rainwater is not used, this leads to the loss of a zero cost water source. The rainwater will be collected in a tank near the roof to allow the supply of any level of the building with zero energy.

When there are many tanks, every floor of the building could have its own tank. But if each of the $m$ floors has its own tank, it necessitates $m$ tanks. This is costly since the installation cost will be very huge unnecessarily. It is advantageous to group the floors in blocks to supply them with the same tank. Let $\eta$ be the number of floors supplied by each tank (for example $\eta=3$ on Figure 3). $k=\frac{m}{\eta}$ is the number of tanks to supply the $m$ floors of the building. Hence, every tank $T_{i}$ is preferably supplying the floors $\eta \times(i-1)$, $\eta \times(i-1)+1, \eta \times(i-1)+2 \ldots, \eta \times(i-1)+\eta-1=\eta \times i-1$. It avoids waste of energy, because the water present in that tank may be probably pumped since the tanks at the bottom.

It would be possible (when there is a need) to drive water from a tank to another. If the tank from which water is conveyed to the other one is above, none energy is necessary.

To summarize it, we present on Figure 3 a generic architecture having $m$ floors supplied by $k$ tanks with $k-1$ surface pumps associated and one immersed pump. On that figure, there are $\forall i \in\{1,2,3, \ldots, k\}$ :

$-V R_{i}$ is the valve opening rainwater from the rainwater pipe to the $\operatorname{tank} T_{i}$.

$-V F_{i}$ is the valve opening water from the tank $T_{i}$ to the floors associated to it.

$-V U_{i}$ is the valve opening water from the urban pipe to the floors associated to the $\operatorname{tank} T_{i}$.

- $S P_{i}$ is the surface pump pumping water from the tank $T_{i}$ to the $\operatorname{tank} T_{i+1}(i \leq k-1)$.

There is also the following valves:

$-V R$ is the valve allowing to evacuate the surplus of rainwater when all the tanks are full.

- $V U$ is the valve driving water from urban distribution network to the floors. It closes whenever the water level in all the $k$ tanks is above the low level $\left(b T_{i}=1\right)$. 


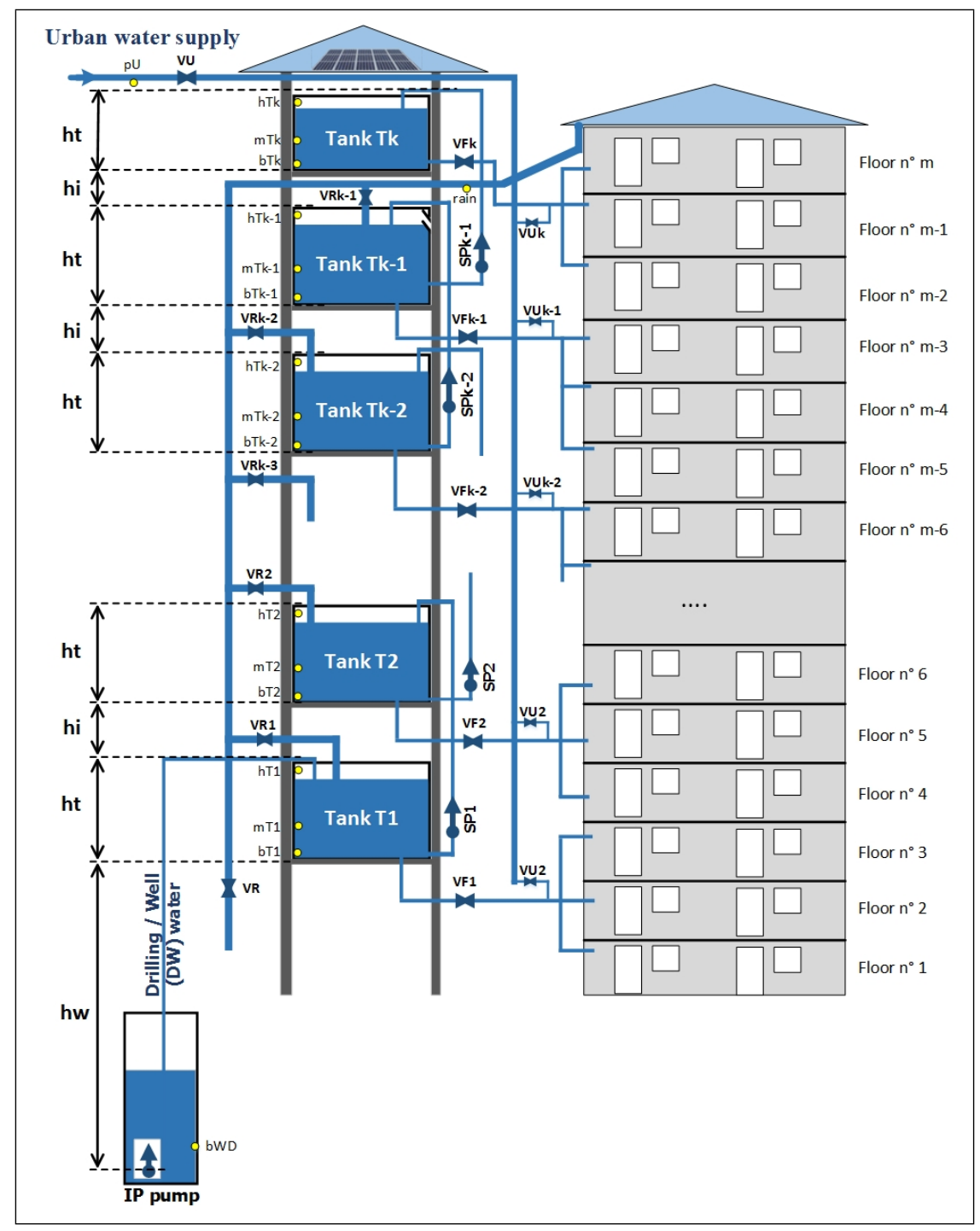

Figure 3. General physical architecture

Some sensors are also used to read and send some information to the controller :

- The sensor rain indicates that it is raining. When it is raining, $r=1$ and all pumping mechanisms stop, except for $T_{k}$. 1).

- The sensor $p U$ indicates that the urban water distribution network is supplied ( $p U=$

- The sensor $b W D$ located inside the well/drilling tells the controller that there is water inside to be pumped by the immersed pump $I P$.

\subsection{Tanks supplying and energy issues}

Whether the pumping energy is zero cost or not, it is necessary and imperative to avoid any waste of energy. The tanks must then be placed and the pumps positioned in 
such a way that they can be operated by avoiding the losses of potential energy. Here, we evaluate this energy to justify the chosen pumping mechanisms.

Let $E_{i, j}$ be the amount of energy necessary to supply the tank $T_{j}$ with the tank $T_{i}$, $i, j \in\{1,2, \ldots, k\}$ and $i \neq j$ with a water volume of $V\left(m^{3}\right)$. Considering that $h i$ is the height between two successive tanks and $h t$ is the height of each tank,

If $i>j$, water of volume $V$ can be conveyed directly from the tank $T_{i}$ to the tank $T_{j}$ without been pumping. Then $E_{i, j}=0$.

If $i<j$, to move the volume $V$ of water from the tank $T_{i}$ to the tank $T_{j}$ directly, the height is $(j-i)(h t+h i)+h t$ and $E_{i, j}(1)=\rho g V[(j-i)(h t+h i)+h t]$. We have:

$$
E_{i, j}(1)=\rho \times g \times(j-i)(h t+h i)+h t
$$

Where $\rho\left(K g / m^{3}\right)$ is the density of water, and $g(N / K g)$ is the gravity of Earth.

When $i<j$, if the same volume $V$ of water is moved from $T_{i}$ to $T_{j}$ passing through the $\operatorname{tanks} T_{i+1}, T_{i+2}, \ldots T_{j-1}$, then $E_{i, j}(2)=E_{i, i+1}+E_{i+1, i+2}+\ldots+E_{j-1, j}=\sum_{l=i}^{j-1} E_{l, l+1}$. $E_{l, l+1}=\rho g V(2 h t+h i)$, which is constant. Then $E_{i, j}(2)=\sum_{l=i}^{j-1} \rho g V(2 h t+h i)=$ $\rho g V(j-i)(2 h t+h i)$ and

$$
E_{i, j}(2)=\rho \times g \times(j-i)(2 h t+h i)
$$

The $\rho g V(j-i) h t$ energy surplus is due to the fact that the water first enters the intermediate tanks being sent higher. The difference between those two amounts of energy is given by $\rho \times g \times V[(j-i)(2 h t+h i)-(j-i)(h t+h i)-h t]$. Then

$$
E_{i, j}(2)-E_{i, j}(1)=\rho \times g \times V(j-i-1) h t
$$

In summary, when $i<j$, since $\rho g V(j-i-1) h t \geq 0, E_{i, j}(2)-E_{i, j}(1) \geq 0$. It is then better to move water directly from the tank $T_{i}$ to the tank $T_{j}$ without passing through the intermediate tanks. But this advantage is apparent because the realization of such an architecture is very difficult due to the following reasons:

- Costly and cumbersome: this requires an amount of $(j-i)$ different water lines equipped with pumps, from the tank $T_{i}$ to the tanks $T_{i+1}, \ldots, T_{j-1}, T_{j}$. For all the building, it requires a total of $1+2+\ldots+(k-1)=\frac{(k-1) k}{2}$ lines. All this is cumbersome and too expensive.

- Unknowing of the floor where the water will be used: the volume $V$ of water may be used elsewhere in building floors, except those supplied by the tank $T_{j}$.

Water should then be pumped steps by steps from tanks $T_{i}$ to tanks $T_{i+1}, i=1,2, \ldots$

\subsection{Number of tanks and energy issues}

If there is only one tank, it implies a too wasting of pumping energy, which may not be available. The main reason is that the rainwater may not be used. In fact, it is difficult to place the highest tank in order to collect rainwater and supply the highest floors. Then, there shall be at least two (02) tanks. 
Let's show that it is better to pump water from tanks to tanks, from the drilling/wells to a specific floor, instead of pumping it up to the highest tank before redistributing it to floors.

\subsubsection{Basic case with two tanks}

Having two $(k=2)$ tanks $T_{1}$ and $T_{2}$, we consider two cases: water is pumped directly from the wells/drilling up to $T_{2}$ (Case 1), and water is pumped from wells/drilling up to $T_{1}$ before beeing moved to $T_{2}$ (Case 2).

The following is the calculation of the amount of energy required to pump a volume $V\left(\mathrm{~m}^{3}\right)$ of water from wells/drilling to the floors. We consider that $V=V_{1}+V_{2}$, where $V_{1}$ is the volume of water used to supply the lower floors and $V_{2}$ the volume used to supply the upper floors.

Case 1: water is pumped directly up to $T_{2}$

Water is pumped directly from the well/drilling to the upper tank $T_{2}$, from which all the building is supplied. $E_{1}$ is the necessary amount of energy for that and is given by:

$$
\begin{aligned}
& E_{1}=\rho \times g(h w+2 h t+h i)\left(V_{1}+V_{2}\right), \text { then: } \\
& \qquad E_{1}=\rho \times g\left[(h w+h t)\left(V_{1}+V_{2}\right)+(h t+h i)\left(V_{1}+V_{2}\right)\right]
\end{aligned}
$$

Case 2: water is pumped to $T_{1}$ before beeing moved to $T_{2}$

In presence of two tanks, water is pumped from the well/drilling to the lower tank $T_{1}$ (supplying the lower floors with $V_{1}$ ) and from $T_{1}$ to the upper tank $T_{2}$ (supplying the upper floors with $\left.V_{2}\right) . E_{2}$ is the necessary amount of energy for that and is given by $E_{2}=\rho \times g\left[(h w+h t)\left(V_{1}+V_{2}\right)+(2 h t+h i) V_{2}\right]$, then :

$$
E_{2}=\rho \times g\left[(h w+h t)\left(V_{1}+V_{2}\right)+(2 h t+h i) V_{2}\right]
$$

Where $h w$ is the height between the well/drilling and the tank $T_{1}$.

\section{Gain of energy}

The difference of energy $E_{1}-E_{2}$ is given by

$$
E_{1}-E_{2}=\rho \times g\left[(h w+h i) V_{1}-h t \times V_{2}\right]=\rho \times g\left[h i \times V_{1}+h t\left(V_{1}-V_{2}\right)\right]
$$

In practice, $h t$ is very less than $h i$. It may be possible to have $h i=6 \times h t$.

If $V_{1}=V_{2}=\frac{V}{2}$ then $E_{1}-E_{2}=\rho \times g \times h i \times \frac{V}{2}>0$

It shows that water needs to be pumped from the well/drilling to $T_{1}$ and secondly from $T_{1}$ to $T_{2}$.

\subsubsection{Generalization with $k$ tanks}

The previous calculations takes into consideration only two tanks. Let's generalize it with $k$ tanks. For this, we consider the general architecture of Figure 3 , and $V=$ $V 1+\ldots+V_{k}, V_{i} \geq 0, \forall i \in\{1,2, \ldots, k\} . V_{i}$ is used by the tank $T_{i}$ to supply the floors numbered $\eta \times i-j, j \in\{0,1, \ldots, \eta-1\}$, where $\eta$ is the number of floors supplied by every tank $T_{i}$.

\section{Case 1: water is pumped directly up to $T_{k}$}


When the volume $V$ of water is pumped from the well/drilling to the tank $T_{k}$ before providing the other tanks $\left(T_{k-1}, \ldots, T_{1}\right)$, the corresponding amount of energy $E_{1}$ is :

$$
\begin{aligned}
E_{1} & =\rho g \sum_{i=1}^{k} V_{i}[h w+h t+(k-1)(h i+h t)]=\rho g(h w+h t) \sum_{i=1}^{k} V_{i}+\rho g[(k-1)(h i+ \\
h t)] \sum_{i=1}^{k} V_{i} & \\
\frac{E_{1}}{\rho g} & =(h w+h t) \sum_{i=1}^{k} V_{i}+(k-1)(h i+h t) \sum_{i=1}^{k} V_{i}
\end{aligned}
$$

Case 2: water is pumped steps by steps from $T_{i}$ to $T_{i+1}$

$E_{2}$ is the amount of energy necessary to pump the volume $V$ of water from tanks to tanks and up to $T_{k}$, pumping only the necessary water volume $\left(V_{i+1}+\ldots+V_{k}\right)$ from $T_{i}$ to $T_{i+1}$, steps by steps. Hence we have :

$$
\begin{gathered}
E_{2}=\rho \times g \times\left(\sum_{i=1}^{k} V_{i}\right)(h w+h t)+\rho \times g \times\left(\sum_{i=2}^{k} V_{i}\right)(h i+2 h t)+\rho \times g \times\left(\sum_{i=3}^{k} V_{i}\right)(h i+ \\
2 h t)+\ldots+\rho \times g \times\left(V_{k-1}+V_{k}\right)(h i+2 h t)+\rho \times g \times V_{k}(h i+2 h t) \\
\frac{E_{2}}{\rho g}=(h w+h t) \sum_{i=1}^{k} V_{i}+(h i+2 h t) \sum_{i=2}^{k} V_{i}+(h i+2 h t) \sum_{i=3}^{k} V_{i}+\ldots+(h i+2 h t)\left(V_{k-1}+\right. \\
\left.V_{k}\right)+(h i+2 h t) V_{k} \Rightarrow \frac{E_{2}}{\rho g}=(h w+h t) \sum_{i=1}^{k} V_{i}+(h i+2 h t)\left(0 V_{1}+1 V_{2}+\ldots+(k-1) V_{k}\right)
\end{gathered}
$$

Then,

$$
\frac{E_{2}}{\rho g}=(h w+h t) \sum_{i=1}^{k} V_{i}+(h i+2 h t) \sum_{i=1}^{k}(i-1) V_{i}
$$

\section{Gain of energy}

The difference of energy $E_{1}-E_{2}$ is then given by:

$$
\frac{E_{1}-E_{2}}{\rho g}=(k-1)(h i+h t) \sum_{i=1}^{k} V_{i}-(h i+2 h t) \sum_{i=1}^{k}(i-1) V_{i}
$$

By reorganizing it into factors of $h i$ and $h t$, we have

$$
\frac{E_{1}-E_{2}}{\rho g}=h i\left[(k-1) \sum_{i=1}^{k} V_{i}-\sum_{i=1}^{k}(i-1) V_{i}\right]+h t\left[(k-1) \sum_{i=1}^{k} V_{i}-2 \sum_{i=1}^{k}(i-1) V_{i}\right][8]
$$

Hence, the difference is given by

$$
\frac{E_{1}-E_{2}}{\rho g}=h i \sum_{i=1}^{k}(k-i) V_{i}+h t \sum_{i=1}^{k}(k-2 i+1) V_{i}
$$

Sign of $E_{1}-E_{2}$ : considering that $k>1$

$\sum_{i=1}^{k}(k-i) V_{i}>0$ and $\sum_{i=1}^{k}(k-2 i+1) V_{i}$ may be negative. But, considering the fact that in reality $h t<h i$ (possibly $\left.h t=\frac{h i}{6}\right)$, it can be shown that $\left|\sum_{i=1}^{k}(k-i) V_{i}\right|>$ $\left|\sum_{i=1}^{k}(k-2 i+1) V_{i}\right|$ and then $E_{2}-E_{1}>0$. 
If $V_{1}=V_{2}=\ldots=V_{k}=\frac{V}{k}=V_{0}$, we have

$$
\frac{E_{1}-E_{2}}{\rho g V_{0}}=h i \sum_{i=1}^{k}(k-i)+h t \sum_{i=1}^{k}(k-2 i+1)
$$

But, $\sum_{i=1}^{k}(k-i)=\frac{k(k-1)}{2}$ and $\sum_{i=1}^{k}(k-2 i+1)=0$, then $\frac{E_{1}-E_{2}}{\rho g}=\frac{k(k-1)}{2} h i \times \frac{V}{k}$.

In other words,

$$
E_{1}-E_{2}=\frac{(k-1)}{2} \rho \times g \times h i \times V>0
$$

In summary, the use of a single tank leads to neglect rainwater and a waste of pumping energy. It is necessary to use at least $k=2$ tanks. To gain energy, water must be pumped from the well/drilling to the lowest tank $T_{1}$ using an immersed pump, from any tank $T_{i}$ to $T_{i+1}(1 \leq i \leq k-1)$ using surface pumps. Also, The rainwater must be collected first in $T_{k}$ then in $T_{k-1}, T_{k-2} \ldots$ to gain in potential energy. This water is not lowered before it is brought up again, by loosing energy.

\section{Logic Control using Grafcet}

From the physical layout architectural water supply system (as shown in Figure 3), we can describe several functional requirements of systems considered in particular contexts. In addition to the case of the whole system, some interesting systems may be obtained considering the fact that there is the absence of one of the following functions: urban electricity supply, drilling/well, urban water supply or battery. In this section, our attention is focused on the whole system from which the solution to other systems cases can be obtained. Initially, let's look at an overview of the Grafcet modeling language. Next, we will propose pieces of grafcet to model the basic functionalities of this system and finish it with the presentation of the synthesis solution strategy.

\subsection{The Grafcet modeling language}

The Grafcet (Graphe Fonctionnel de Commandes et d'Etapes/Transition), a graphic language for modeling automated systems, is the most international formalism used for high-level description of complex sequential systems [5]. It is widely used in several domains such as home automation, automotive, power generation, manufacturing, etc. A grafcet specifies the behavior of a logic control system. This language has been standardized by the International Electrotechnical Commission IEC 60848 [3], and is understandable and readable compared to other specification languages as Petri net, Relay ladder, Instruction list, etc.

A grafcet (program written in Grafcet language) is a graph that consists of two types of nodes: steps and transitions. A step is represented by a square, while a transition is represented by a horizontal line. The initial steps have a double square. Directed edges are necessarily used to connect steps to transitions or transitions to steps. Each step may be associated with several actions which represent the outputs of a Grafcet graph. An action is symbolized by a rectangle which is connected to a step. The same action can be connected to many steps and it becomes true if at least one of those steps is active. Some 
elements are used to separate structurally steps and transitions: when there are many steps in the upstream of a transition, a "junction AND" represented with a double-line is put between those steps and this transition. A "distribution AND", represented with a double-line, is used to separate a transition with many steps when this transition has many steps in the downstream. When there are many transitions in the upstream of a step, a "junction OR" represented with a simple horizontal line is used. A "distribution OR" also represented with a simple horizontal line is used to separate a step to many transitions that are in the downstream of this step.

The Grafcet evolution from the initial state is done by firing transitions according to the following five evolution rules [3]:

- Rule 1: At the initial time, all the initial steps are active; all the other steps are inactive.

- Rule 2: A transition is enabled when all the steps that immediately precede this transition are active. A transition is fireable when it is enabled and when the associated transition condition is true. A fireable transition must be immediately fired.

- Rule 3: Firing a transition provokes simultaneously the activation of all the immediately succeeding steps and the deactivation of all the immediately preceding steps.

- Rule 4: When several transitions are simultaneously fireable, they are simultaneously fired.

- Rule 5: When a step shall be both activated and deactivated, by applying the previous evolution rules, it is activated if it was inactive, or remains active if it was previously active.

These rules enable the calculation of the subsequent state and the corresponding output signals caused by an input event.

\subsection{Grafcet specification model for the system}

Here, we propose some general Grafcet models for the specification of processes under control of the logic controller whose the general architecture is presented in Figure 3. In Figure 2, there is the I/O specification of intermediary tanks controller. This is a part of entire controller which should control the modeling of water providing of tanks \& floors according to multilevel hierarchical priority access to water, and the switching process between water \& energy sources.

\subsubsection{Grafcet modeling water providing of tanks}

According to the description of the tanks supplying given in subsections $2.2 \& 2.3$, there are three cases of tanks:

- The lower tank $T_{1}$ : water is pumped with the immersed pump $I P$.

- The highest tant $T_{k}$ : water is pumped with a surface pump $S P_{k-1}$.

- The other $T_{i}(2 \leq i \leq k)$ tanks: water is pumped with the same condition as $T_{k}$, and the filling of $T_{i}$ with rainwater is conditioned by the fact that $T_{i+1}$ is already full $\left(h T_{i+1}=1\right)$.

On transitions receptivities of Grafcet, we sometimes use the notation "!" to indicates the negation logical operator. 


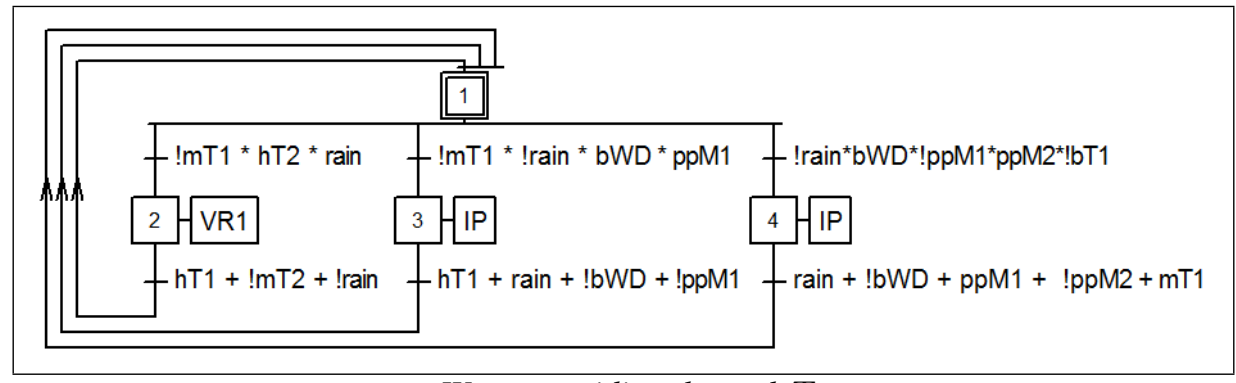

a-Water providing the tank $T_{1}$

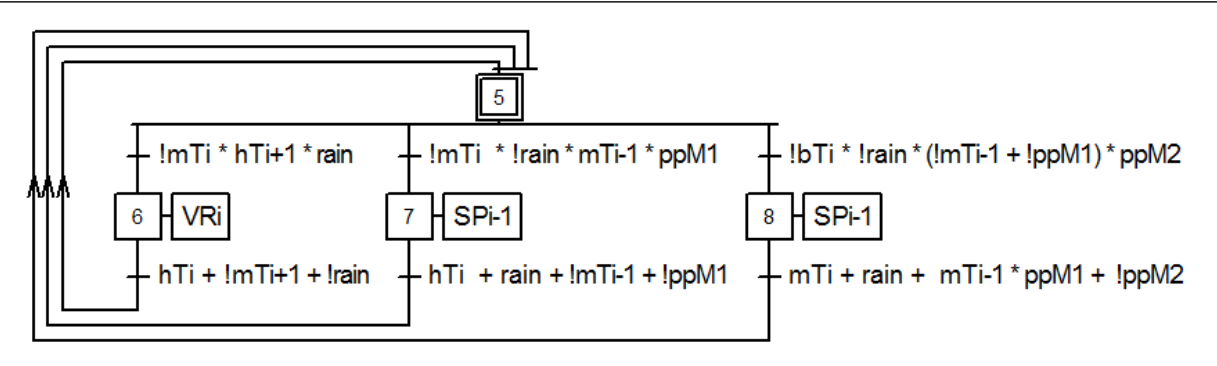

$b$-Water providing the tank $T_{i}$

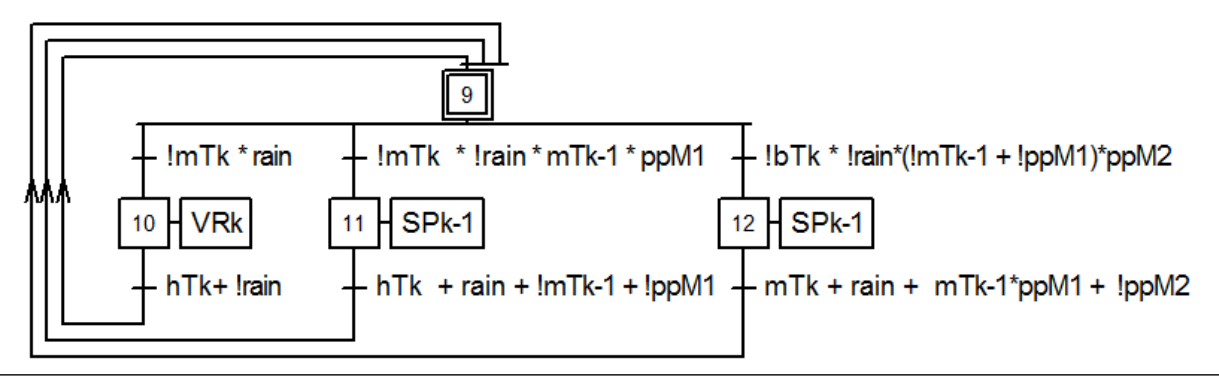

c-Water providing the tank $T_{k}$

Figure 4. Grafcet specification of water providing tanks

The water providing of tanks is well specified during the modeling of the switching process presented in 4.2.3. This process can be specified with the Grafcet model of Figure 4. Variables $p p M 1$ and $p p M 1$ indicate the presence of pumping energy. $p p M 1=s r l+$ $\overline{s r l} * b c l$ concerns the first mode inherent to pumping with zero energy cost (with sun or with storage batteries) and the variable $p p M 2=\overline{s r l+b c l} * p U E S$ is related to pumping with energy cost, where $p U E S$ informs on the presence of urban electricity.

Figure 4.b presents the providing of any tank $T_{i}$ : When $T_{i}$ lacks water $\left(m T_{i}=0\right)$ and if there is rainwater ( rain $=1$ ), the valve $V R_{i+1}$ is opened and $T_{i}$ is provided until it is full $\left(h T_{i}=1\right)$. If there is not rainwater $($ rain $=0)$, the second alternative is used when $T_{i-1}$ is provided $\left(m T_{i-1}=1\right)$ and there is power to supply the surface pump $S P_{i}$. The action $S P_{i-1}$ is put on to pump water from $T_{i-1}$ to $T_{i}$.

It is the same with $T_{1}$ (Figure 4.a) except that water is pumped from $I P$ pump. Also, $b W D$ indicating the level of water in the drilling/wells. For $T_{k}$, when it is raining, the opening of $V R_{k}$ is not subject to the conditions $h T_{k+1}$ (the tank $T_{k+1}$ does not exists), but only to the condition $\operatorname{rain} * ! m T_{k}$ (Figure 4.c). 
To manage the fact that when it is raining, tanks are filled from the highest to the lowest, we consider that $T_{k}$ is filled with rainwater with the condition $m T k *$ rain (receptivity of the transition going from the step 9 to the step 10 ); and $\forall T_{i}, i \in\{1, \ldots, k-1\}$ the condition to fill $T_{i}$ with rainwater is $! m T_{i} * m T_{i+1} *$ rain (receptivity of the transition from the step 5 to the step 6$)$, so $T_{i+1}$ must be fulfilled first $\left(h T_{i+1}=1\right)$.

In addition, the action $V R$ allows the evacuation of the surplus of rainwater when all the tanks are full $\left(h T_{1} * h T_{2} * \ldots * h T_{k}=1\right)$. It stops when there exists a tank $T_{j}$ whose water level is below the medium level $\left(m T_{j}=0\right)$. In this case, the filling process of $T_{j}$ starts automatically. To avoid damages between the time all tanks are full and when at least one tank has a water level below the medium, exhaust outlets may be put on each tank. The process of opening and closing $V R$ is specified with the Grafcet model of Figure 5 .

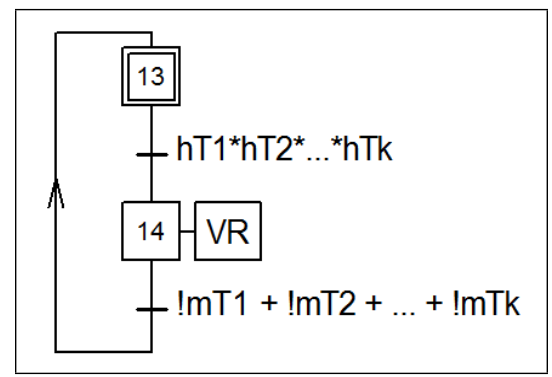

Figure 5. Grafcet specification of opening/closing the exhaust valve $V R$

\subsubsection{Grafcet modeling water providing of floors}

Every floor is attached to a tank $T_{i}$ from which it is provided.

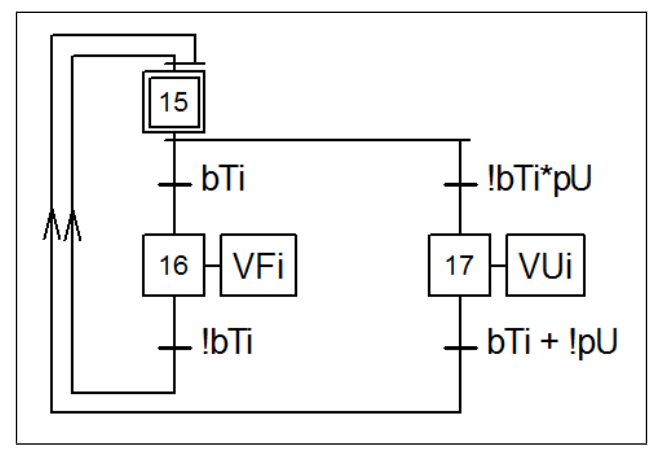

Figure 6. Gafcet specification of water providing floors

The valve $V F_{i}$ should remain opened while there is water inside $T_{i}\left(b T_{i}=1\right) . V F_{i}$ is closed as soon as the tank is empty $\left(b T_{i}=0\right)$, in which case the urban distribution network takes over with the valve $V U_{i}$ when it is supplied $(p U=1) . V U_{i}$ is also closed as soon as $T_{i}$ becomes supplied again $\left(b T_{i}=1\right)$ or the urban network becomes unavailable $(p U=0)$.

The conditions $b T_{i}, ! b T_{i}, ! b T_{i} * p U$ and $b T_{i}+! p U$ present in the Grafcet specification model of Figure 6 are then justified. 
Table 1. Truth table of $M X 1$ and $M X 2$ multiplexers

\begin{tabular}{|ccccc|c|}
\hline \multicolumn{5}{|c|}{ Addresses: $j=j_{\lambda} j_{\lambda-1} \ldots j_{2} j_{1}$} & $E_{\text {out }}=E_{j}$ \\
\hline$M X_{\lambda}$ & $M X_{\lambda-1}$ & $\ldots$ & $M X_{2}$ & $M X_{1}$ & Output \\
\cline { 1 - 5 } & 0 & $\ldots$ & 0 & 0 & None \\
0 & 0 & $\ldots$ & 0 & 1 & $E_{1}$ \\
$\ldots$ & $\ldots$ & $\ldots$ & $\ldots$ & $\ldots$ & $\ldots$ \\
1 & 1 & $\ldots$ & 1 & 1 & $E_{p}$ \\
\hline
\end{tabular}

\subsubsection{Grafcet modeling switching process between energy sources}

When modeling water providing of tanks (4.2.1) and water providing floors (4.2.2), the switching process between water sources is handled by activating/deactivating the gates control. Because every pump can function with many energy sources, the switching process between energy sources issue should also be solved. For that, it is necessary to use another electronic component electrically controllable, as multiplexers for example.

With $p$ sources of energy, we rank them from the cheapest to the most expensive: $E_{1}, E_{2}, \ldots, E_{p}$. We associate a variable $p E_{j}$ (presence of energy to the source $E_{j}$ ) to every power source $E_{j} \cdot p E_{j}=1$ when the source $E_{j}$ has energy $(j=1,2, \ldots, p)$.

A mechanism implemented by a multiplexer is then putted in place. It permits to select between the available sources of the $p$ sources a particular source $E_{j}$ having the lowest cost, to be connected on the multiplexer output $E_{\text {out }}$.

Let $\lambda=\left\lceil\log _{2} p\right\rceil$, such that $p<2^{\lambda}$ (there should be one emty energy in input). We define the variables $M X_{1}, \ldots, M X_{\lambda-1}$ used in input of a multiplexer $M X$ for the selection between the sources $E_{1}, E_{2}, \ldots, E_{p}$, as presented on Figure 7.

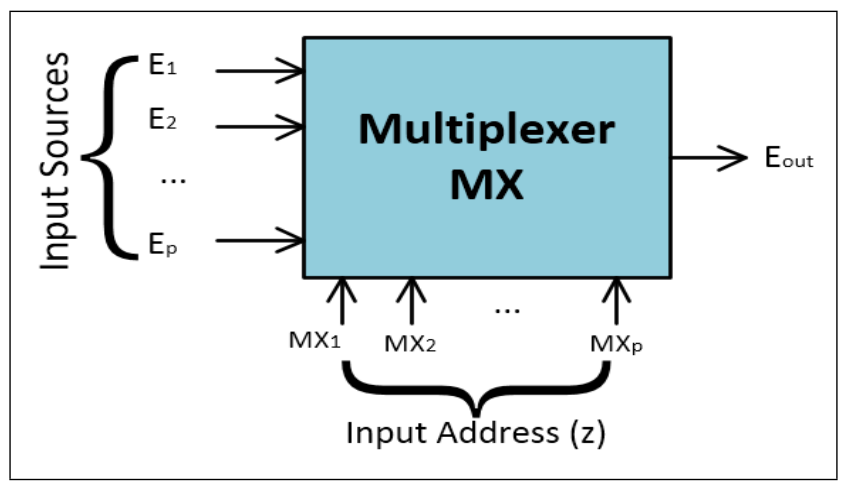

Figure 7. Multiplexer $M X$ for power sources switching

To select a particular source $E_{j}$ (i.e. to connect $E_{j}$ to $E_{\text {out }}$ ), $\forall j \in\{1,2, \ldots, p\}$ we can have $j=\left(j_{\lambda}, j_{\lambda-1}, \ldots, j_{1}\right)=\left(M X_{\lambda}, \ldots, M X_{1}\right)$, where $\left(j_{\lambda}, j_{\lambda-1}, \ldots, j_{1}\right)$ is the binary representation of $j$. We then define the actions $M X_{j_{z}}(z \in\{1,2, \ldots, \lambda\})$, which are activated when $j_{z}=1$ in that representation of $j$. Table 1 presents the truth table of that mechanism.

As long as there is at least one available source, $E_{\text {out }}$ remains supplied until none source has power. Also, when $E_{\text {out }}$ is not supplied, it becomes supplied as soon as one source of energy becomes available. The energy is provided independently of the fact that $E_{\text {out }}$ is used by a pump or not. It can be specified by the grafcet of Figure 8. 


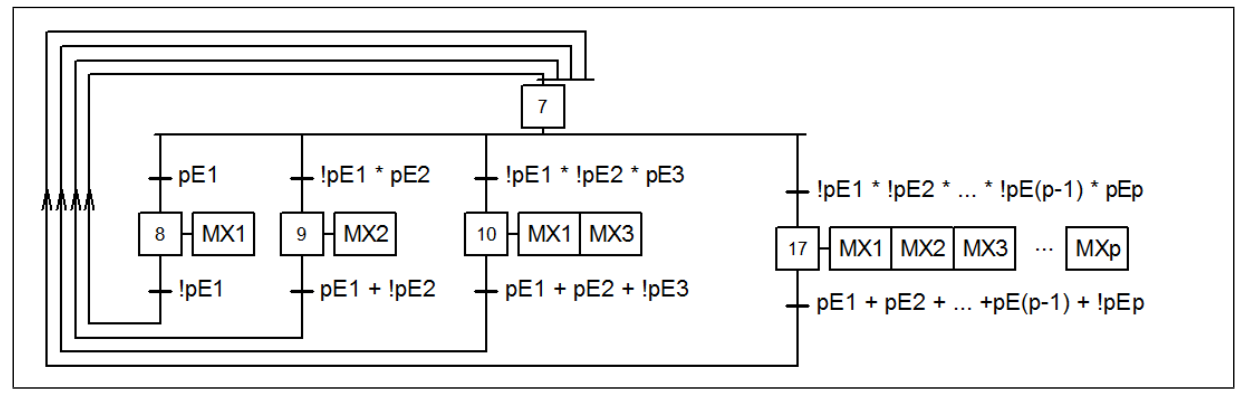

Figure 8. Grafcet specification of the switching process between power sources providing a pump

In the specific context of water providing of households, the sensors $p E_{j}$ correspond to the signals $s r l, b c l, p U E S, \ldots$ whereas the sources $E_{j}$ are $P V S, B S, U E S, \ldots$ with $j \in\{1,2, \ldots, p\}$. Here, we consider that all the pumps (surface $\&$ immersed) are supplied with the same sources of energy. In contrary, it is possible to have many types of pumping sources $(24 \mathrm{vols}, 220 \mathrm{vols}, \ldots$... $)$. Sources can then be reorganized in groups and this switching mechanism can easily be applied to each group.

\subsection{Synthesis solution strategy}

Given the technical design specifications of the water supply system, the grafcet specification model is derived from. We present in this subsection the synthesis process for logical control systems specified in Grafcet. A grafcet model can be realized on programmable controllers (such as microcontrollers or PLCs). However, they do not allow a direct implementation on control targets like microcontrollers, which cost comparatively less than PLCs. For this, we have conducted research on the automatic and robust synthesis of logic controllers specified in Grafcet language and realized on microcontroller targets.

A program synthesis tool is then designed for microcontrollers, according to the Grafcet algebraic equations approach broadly presented in sub-section 4.4.

Referring to Figure 9 , the synthesis process can be split into multiple steps which are broadly described as follows:

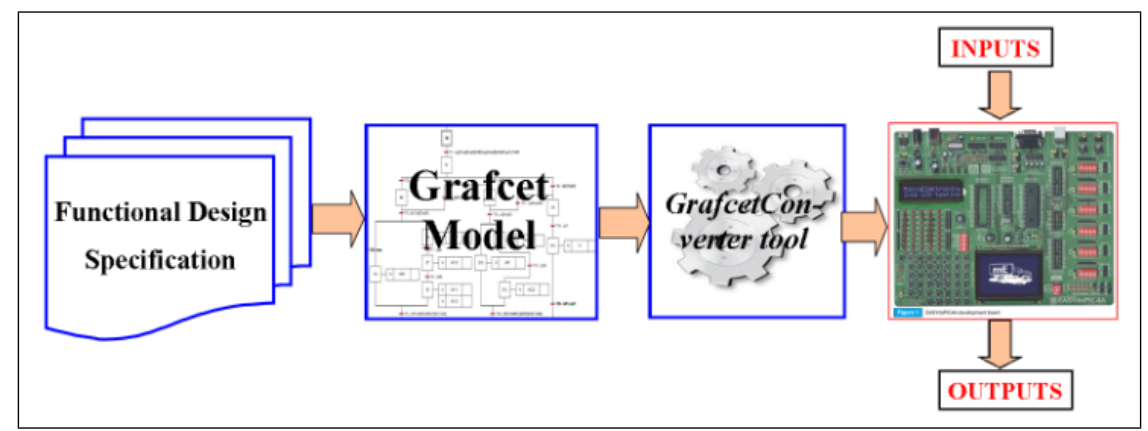

Figure 9. Synthetic approach solution 
- Step 1. Functional Design Specification (FDS) of the system :

The design and development of any system starts with the description of requirements. An FDS is the most important step in the design of any control system. It provides details of the proposed solution to be implemented, to meet user requirements. Thus, FDS is the documentation that defines what the system should do and what functions and facilities should be provided by this system in order to satisfy the requirements. After the FDS specifying all the functions (e.g. pumping, switching, measuring ...), the objects (sensors, pumps, switches ...) and sequential interactions which are associated with the system, the controller is broadly specified with an Inputs/Outputs system presenting all the signals in input and all actions in output.

- Step 2. Grafcet model :

The next step is to represent the technical specification of the system by Grafcet model. We propose UniSim software tool in order to edit Grafcet chart [8]. It is a graphical user interface (GUI) that offers gallery of specific graphical objects (shapes) for all Grafcet elements (such as steps, transitions, transition-conditions and actions). The user can easily select these graphical objects, place them onto a drawing page and attach them together in order to create specific grafcet charts. Furthermore, UniSim tool permits to reformat or serialize Grafcet data into XML format [13], this option ensures that this information can be easily processed by another software application (interoperability property), especially the one that we have realized.

- Step 3. GrafcetConverter tool :

We have built this software tool in order to directly read and extract the Grafcet data from XML format file and generate the appropriate program according to the Grafcet algebraic equations approach presented in subsection 4.4. This program in C language is ready to be compile by the appropriate compiler to build the corresponding binary program. Furthermore, GrafcetConverter tool provides a simulation engine with which we can simulate the Grafcet program and verify whether it meets the requirements or not before generating the C-program for the selected microcontroller. This tool can generate code for microcontrollers, especially the EASYdsPIC4 of the Microship dsPIC family [14].

- Step 4. Integrated Circuit :

We are using the EASYdsPIC4A microcontroller, a full-feature and very powerful development system for PIC microcontrollers from Microchip [14] that holds a dsPIC30F4013 microprocessor. In $\mathrm{C}$ language, we have implemented the Grafcet interpretation algorithm [5] using the MPLAB IDE. The board is programed by generating and transferring a binary program to the EEPROM board through USB cable or RS-232 COM port. When the code is uploaded in the board and the board reinitialized, the board runs and serves as the sit control of the system.

\subsection{Grafcet implementation with algebraic equations}

In the program outputted by the synthesis tool, to make sure that the evolution of the Grafcet situation is done according to the Grafcet evolution rules, we automatically generate Grafcet algebraic equations as stated by J. Machado et al in [2]. They use algebraic equations as a common model for simulation and formal verification to obtain a safe controller specification that will be implemented on PLC. 
This control program runs according to a scan-based perception which is an effect of the PLC cyclic mode of operation. Figure 10 presents the scan-based cycle processed in every step of the microcontroller $(\mu \mathrm{C})$ during its sequential execution.

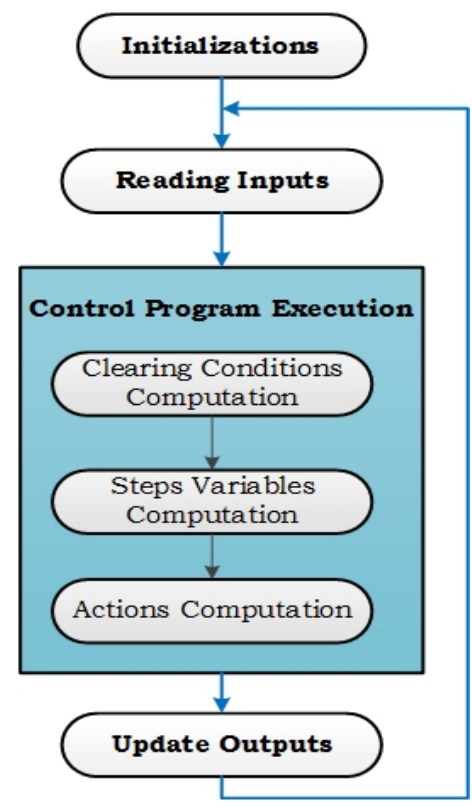

Figure 10. $\mu$ C/PLC Scan cycle

The Grafcet algebraic equations generated when producing a control program are defined as follows:

Let $C C(t r)$ (Clearing Condition) be a Boolean variable associated to every transition tr of a Grafcet. A transition tr can be cleared if it is enabled and if its associated transition condition $T C(t r)$ is true. $C C(t r)$ is calculated as shown on equation E15 as follows:

$$
C C(t r)=\left(\prod_{j=1}^{m} X_{j}^{t r}\right) \times T C(t r)
$$

where :

$-X_{j}^{t r}$ is the step activity Boolean variable associated to step $j$ and directly preceding transition $t r$,

$-T C(t r)$ is the transition condition associated to transition $t r$ and

$-m$ is the number of steps immediately preceding the transition $t r$.

Any Boolean step activity associated to each Grafcet step is computed as follows:

$$
X_{i}(0)=\left\{\begin{array}{cc}
1 & \text { if } X_{i} \text { is an initial step } \\
0 & \text { else }
\end{array}\right.
$$




$$
X_{i}(t+1)=\sum_{j=1}^{p} C C\left(t r_{j}^{i-}\right)+X_{i}(t) \times \prod_{j=1}^{q} \overline{C C\left(t r_{j}^{i+}\right)}
$$

where :

$-X_{i}(t)$ is the step activity variable of step $i$ in the $t^{t h}$ scan cycle,

$-X_{i}(t+1)$ is the step activity variable of step $i$ in the $(t+1)^{t h}$ scan cycle,

$-p$ is the number of transitions directly preceding the step $i$,

$-q$ is the number of transitions directly succeeding the step $i$,

$-C C\left(t r_{j}^{i-}\right)$ is the clearing condition of transition $j$, directly preceding the step $i$ and

$-C C\left(t r_{j}^{i+}\right)$ is the clearing condition of transition $j$, directly succeeding the step $i$.

For actions computation, a Boolean variable $A$ is associated to each action $\mathcal{A}$. An action $\mathcal{A}$ may be associated to several steps and its value $A(t)$ is obtained by computing the $O R(+)$ operation of the step activity variables $X_{i}^{\mathcal{A}}, i=1,2, \ldots, h$ of $h$ steps to which this action is associated. Hence,

$$
A(t)=\sum_{i=1}^{h} X_{i}^{\mathcal{A}}(t)
$$

Where $X_{i}^{\mathcal{A}}(t)$ is the activity variable of a step to which the action $\mathcal{A}$ is associated.

\section{Case study}

In this section, we present a case study, describing the physical layout architecture of a water \& energy supply system and its synthetic scheme.

\subsection{System Features}

Figure 11 illustrates the water distribution system for a six-floor building, consisting of: several water sources $(n=3)$, several sources of pumping energy $(p=5)$, several water access valves with different priority levels, control system, in addition to two $(k=$ 2) water tanks $\left(T_{1}\right.$ and $\left.T_{2}\right)$.

As described in the general case (sub-section 3.1), we consider:

\section{Three water sources:}

- Urban network water distribution,

- Well/Drilling Water and

- Reserve of rainwater.

\section{Five sources of pumping energy:}

- Source $E_{1}$ or $P V S$ : is 24 volts solar panel. Its presence is indicated by the electrical power sensor $\mathrm{srl}$.

- Source $E_{2}$ or $B S$ : is 24 volts battery, can be charged with solar power. The electrical power sensor $b c l$ indicates its presence. 
- Source $E_{3}$ : is 220 volts AC to 24 volts DC transformer, from Source E5. The electrical power sensor $p U E S$ indicates its presence.

- Source $E_{4}$ : is inverter generator, provides 220 volts. Its presence is known thanks to the electrical power sensor $b c l$.

- Source $E_{5}$ or $U E S$ : is public electricity network, provides 220 volts. Its presence is known thanks to the electrical power sensor $p U E S$.

\section{Pumping mechanisms}

- The surface pump $S P$ is setup for 24 volts DC; the power supply is provided either by direct solar panels E1, or by solar charged battery $\mathbf{E 2}$ or by transformer E3. $S P$ permits to pump the water from $T_{1}$ up to $T_{2}$.

- Immersed pump $I P$ is setup for 220 volts; the power supply is provided either by the inverter $\mathbf{E 4}$ or by the urban network E5. IP permits to pump the well water up to $T_{2}$.

Water access valves: $V U, V R, V R_{1}, V F_{1}, V F_{2}, V U_{1}$ and $V T_{2}$.

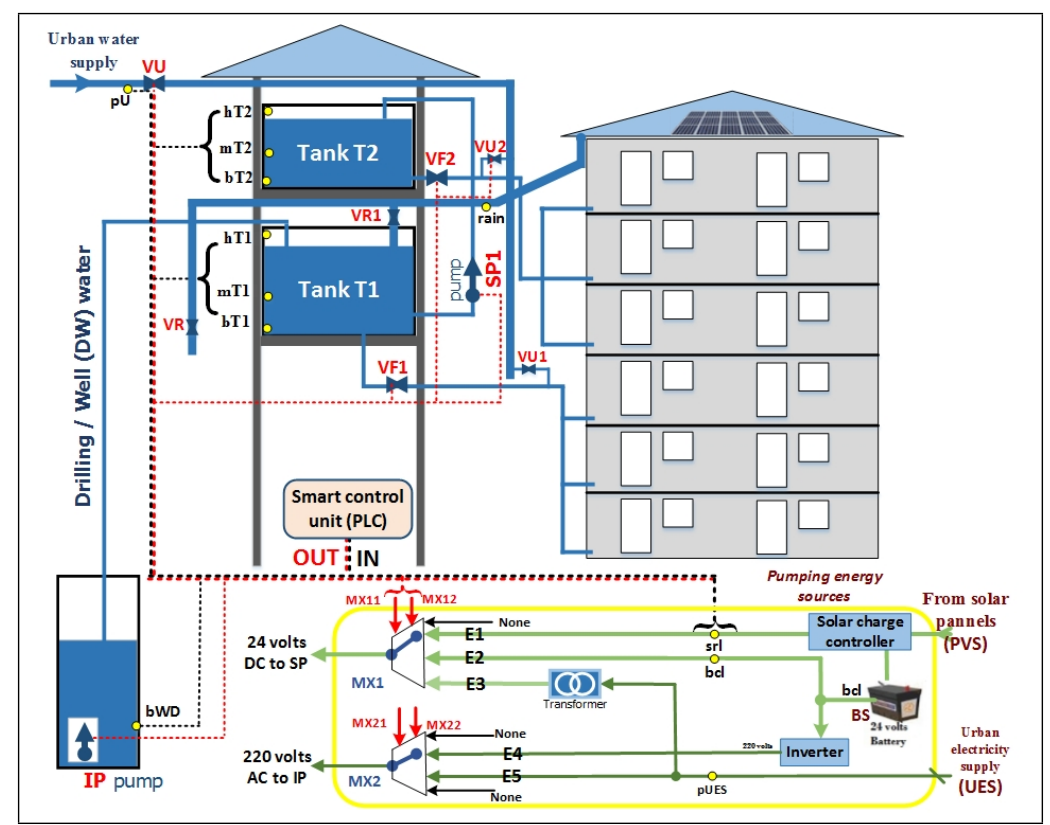

Figure 11. Synthetic diagram of the system

This architecture of this case study works according to the detailed description presented in Section 2 where there are water storage of tanks (2.1), the ways of conveying water from sources to tanks: energy-free filling with rainwater (2.2), the pumping based filling (2.3) and pumping purchased to the urban distribution network (2.4). The switching process between power sources and valves is then presented.

Multiplexers are used as presented in 4.2 .3 for the switching process between sources of pumping energy. The surface pump $S P$ is supplied either by $E 1, E 2$ or $E 3$. The selection of the desired source among them can then occur by means of a multiplexer switch $M X_{1}$. The immersed pump $I P$ is supplied either by $E 4$ or $E 5$. Hence, the selection of the desired source can occur by means of a multiplexer switch $M X_{2}$. 


\subsection{The logic control system}

The water distribution system is completely controlled by a smart control system (controller). It has its proper power supply that makes it autonomous.
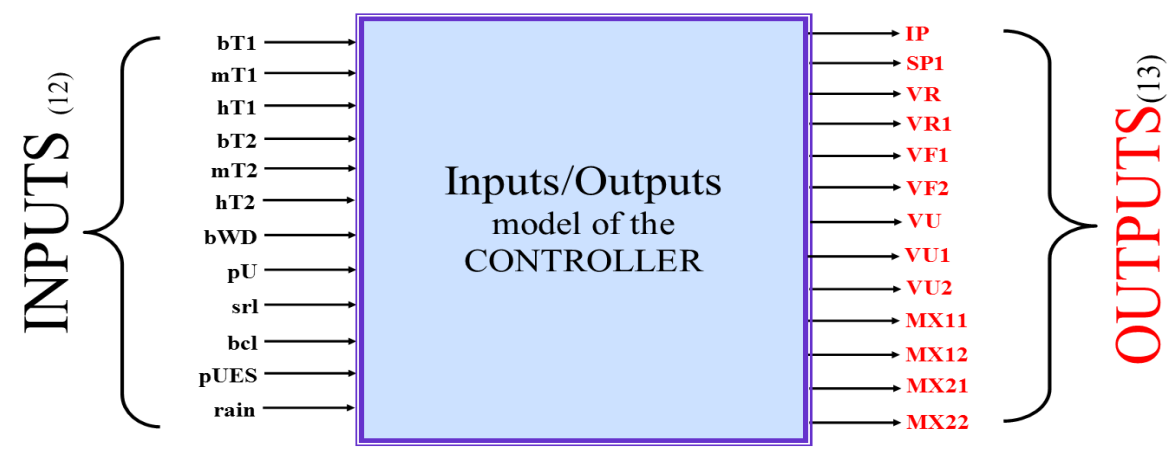

Figure 12. Input/Output model of the case study logic control system

The input points of the controller are connected to sensors, which permit to report events and transmit this information as signals to the controller. The 13 digital input sensors used in our system are summarized as follows:

- Water level sensors : $b T_{1}, m T_{1}, h T_{1}, b T_{2}, m T_{2}, h T_{2}, b W D$.

- Pressure sensors : $p U$, rain.

- Electrical power sensors: $s r l, b c l$ and $p U E S\left(p E_{1}=s r l, p E_{2}=b c l, p E_{4}=b c l\right.$, $\left.p E_{5}=p U E S\right)$.

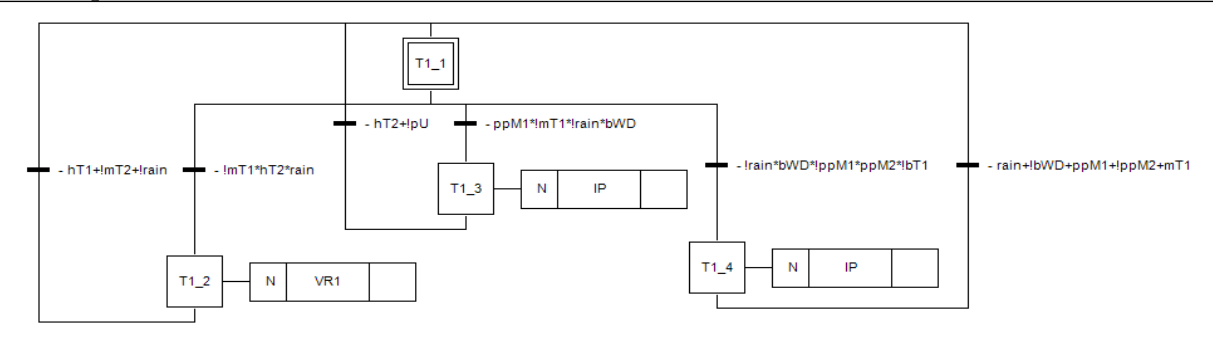

a-Specification of water providing $T_{1}$

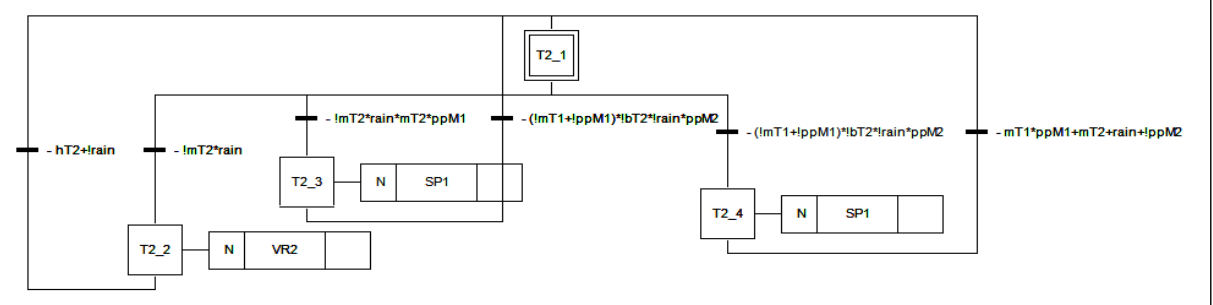

b-Specification of water providing $T_{2}$

Figure 13. Case study: Grafcet specification of tanks providing 


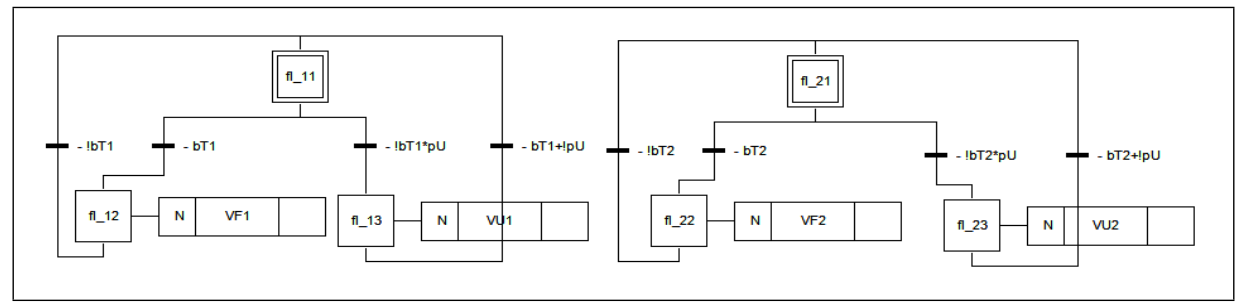

a-Specification of opening and closing the $V F$ 's \& VU's valves

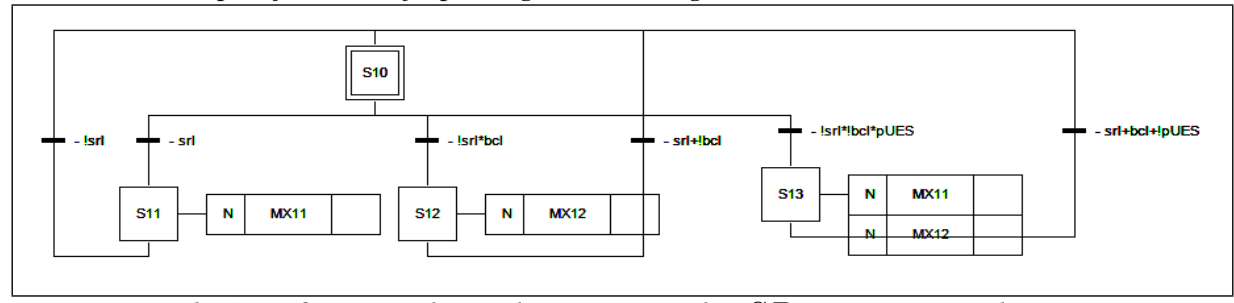

$b$-Specification of switching process for $S P_{1}$ energy providing

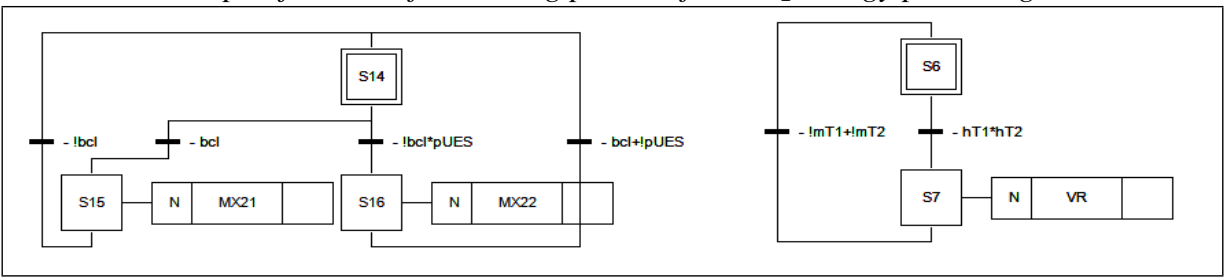

c-Specification of switching process for IP pump and the $V R$ valve

Figure 14. Case study: Grafcet specification of valves and swithing process

The controller will then read, analyze the input signals and activate actions to be activated, according to the $\mu \mathrm{C} / \mathrm{PLC}$ scan-base cycle of Figure 10. These generated actions are interpreted as output signals transmitted to output devices (such as actuators and relays) to control the water circulation system. The 13 digital output devices used in our system are :

- Inductors : $I P, S P$.

- Relays : $V R, V R_{1}, V F_{1}, V F_{2}, V U, V U_{1}, V U_{2}$.

- Inputs of multiplexer switches : $M X_{11}$ and $M X_{12}$ (for $M X_{1}$ multiplexer to select either $E 1, E 2$ or $E 3$ pumping energy sources), $M X_{21}$ and $M X_{22}$ (for $M X_{2}$ multiplexer to select either $E 4$ or $E 5$ pumping energy sources).

The Input/Output model of that logic control system is presented on Figure 12. In that model, power sources are replaced by $M X_{11}, M X_{12}, M X_{21}$ and $M X_{22}$ which permit to command the selection of one of the power sources.

\subsection{Grafcet specification model for the system}

From functional specifications of the water supply system described in the previous subsection, we derive the corresponding Grafcet specification model, according to the general method described in subsection 4.2. The Grafcet specification of the functioning of this logic control system is shown on the following figures : Figure 13 and Figure 14.

As described in the synthesis process in 4.3, when the control program generated from the Grafcet specification model of the water supply system is compiled an sent to 
the EASYdsPIC4A board, this board serves as the core of the smart control unit. Thus, it receives input signals from the sensors (presence of water, pressure, and electric power), analyzes them and generates output signals in form of commands or actions to perform specific acts (open/close valves, turn on/off the pumps or choose a power source).

\section{Conclusion and Perspectives}

In this paper, we have presented the ability to exploit ICT advantages in order to resolve critical issues ongoing in developing countries, particularly households water supplying with electrical energy issue. We have then designed a generic and sophisticated control system that permits the analysis and the study on the availability of several energy \& water sources having different costs; and automatically take a decision on the best source to be selected for ensuring continuous water service in the whole building without any interruption and with the lowest cost. The pumping mechanisms and the switching process between power sources is based on energy calculations which guarantee a considerable reduction in pumping energy.

Furthermore, the designed architecture of the water distribution system presents a generic concept of water supply that may be integrated in a building project as well as in an already existing building, having several floors and supplied through several tanks. The controller of such events-driven systems can be realized thanks to the synthesis tool, GrafcetConverter, that reads the Grafcet model of the system under study and produces a C-program which, after compilation and loading in the board, runs at each step by reading inputs and performing the necessary actions

\section{References}

[1] G. De Tommasi, A. Pironti, "An educational open-source tool for the design of IEC 611313 compliant automation software", IEEE International Symposium on Power Electronics, Electrical Drives, Automation and Motion, 2008, pp. 486-491.

[2] Machado J, Seabra E, Campos JC, Soares F, Le C., "Safe controllers design for industrial automation systems", Computers \& Industrial Engineering, 2011, Vol. 60(4), pp.635-653.

[3] IEC 60848, "GRAFCET specification language for sequential function charts (3rd ed.)", IEC, 2012.

[4] Frank Schumacher, Sebastian Schröck, Alexander Fay, "Tool support for an automatic transformation of GRAFCET specifications into IEC 61131-3 control code", IEEE-ETFA, 2008, pp. 486-491.

[5] R. DAVID, "Grafcet: A Powerful Tool for Specification of Logic Controllers", IEEE Transactions on Control Systems Technology, vol. 3, num. 2, 1995, pp. 253-268.

[6] Institut NATional DE LA STATistiQue, "Qualité des eaux de surface et souterraines dans la ville de Yaoundé et son impact sanitaire", Journal, July 2013, pp. 2-3.

[7] MINEPAT, "LES ÉNERGIES RENOUVELABLES : une piste à explorer", La lettre économique du Cameroun, June 2015, pp. 2-3.

[8] "UNISIM", "UNISIM WEBSITE", http://wpage.unina.it/detommas/unisim/, 2006, Accessed: Aug. 2016. 
[9] IEC 61131-3, "Programmable Controllers - Part 3: Programming languages (3rd Ed.)", International Electrotechnical Commission, Feb. 2013.

[10] Helena M. RAMOS, Filipe VIEIRA, Dídia I. C. COVAS, “Energy efficiency in a water supply system: Energy consumption and $\mathrm{CO} 2$ emission ”, Water Science and Engineering, 2010, 3(3):pp. 1659-1668.

[11] Tricarico Carla, Morley Mark S., Gargano R., Kapelan Zoran, de Marinis G., SAVIC, DRAGAN, Granata F., "Integrated optimal cost and pressure management for water distribution systems", 12th CCWI2013, Procedia Engineering 70, 2014, 3(3):pp. 331340.

[12] AFCET, "Normalisation de la représentation du cahier de charges d'un automatisme logique", Tech. Rep., Nov-Dec 1977, pp. 61-62.

[13] PLCopen Technical Comittee 6, "XML Formats for IEC 61131-3”, Technical report, 2005.

[14] MikRoEleCtRONIKA, "EasydsPIC4A Development http://www.mikroe.com/products/view/313/easydspic4a-development-system/, Accessed: Aug. 2015. 